\title{
An "Ideal" Kyoto Protocol: Emissions Trading, Redistributive Transfers and Global Participation
}

\author{
By
}

Arthur J. Caplan

Department of Economics, Utah State University, 3530 Old Main Hill, Logan, UT 84322-3530, USA.

Richard C. Cornes

School of Economics, University of Nottingham, University Park, Nottingham NG7 2RD, UK.

and

Emilson C. D. Silva

Department of Economics, Tulane University, New Orleans, LA 70118-5698, USA.

May 10, 2002

\begin{abstract}
We demonstrate that an interregional policy scheme featuring trading of carbon dioxide emissions, redistributive resource transfers and global participation, a scheme which we call "Ideal Kyoto Protocol," yields an efficient equilibrium allocation for a global economy. An altruistic international agency - say, the Global Environment Facility - should operate the resource transfer mechanism. In addition, regional governments should be able to make independent policy commitments regarding how to control regional emissions of carbon dioxide in anticipation of the redistributive transfers. Our efficiency result suggests that the USA should be "bribed" to reverse its decision of not participating in the Kyoto Protocol.
\end{abstract}

Acknowledgements: We would like to thank Daniel Arce, Harvey Lapan, Todd Sandler and two anonymous referees for very helpful comments and suggestions, which greatly improved the paper. Silva also wishes to thank the Tulane Committee on Research Summer Fellowships for partially funding this research. 
An "Ideal” Kyoto Protocol: Emissions Trading, Redistributive Transfers and Global Participation

May 10, 2002

\begin{abstract}
We demonstrate that an interregional policy scheme featuring trading of carbon dioxide emissions, redistributive resource transfers and global participation, a scheme which we call "Ideal Kyoto Protocol," yields an efficient equilibrium allocation for a global economy. An altruistic international agency - say, the Global Environment Facility - should operate the resource transfer mechanism. In addition, regional governments should be able to make independent policy commitments regarding how to control regional emissions of carbon dioxide in anticipation of the redistributive transfers. Our efficiency result suggests that the USA should be "bribed" to reverse its decision of not participating in the Kyoto Protocol.
\end{abstract}




\section{Introduction}

The Kyoto Protocol to the United Nations Framework Convention on Climate Change, completed on December 10, 1997, called for the creation of three mechanisms to effectively control global greenhouse gas emissions. There should be an emissions trading mechanism, ${ }^{1}$ which in its initial phase would include a subset of OECD and Eastern European countries (referred to as Annex I countries), a "clean development" mechanism, which in a later stage would allow developing countries to participate in emissions trading, and a financial mechanism, which would facilitate transfers of income, technology and other valuable resources from rich to poor countries. The idea behind the clean development mechanism is articulated in Article 11 of the Protocol, whereby (1) "[developing] countries will benefit from project activities resulting in certified emissions reductions," and (2) "[developed countries] may use the certified emissions reductions accruing from such project activities to contribute to compliance with part of their quantified emission limitation and reduction commitments." As for the financial mechanism, the Conference of the Parties to the United Nations Framework Convention on Climate Change, which represents the supreme body of the Convention, has delegated the responsibility of operating such a mechanism to the Global Environment Facility (GEF). The GEF was established in 1990 by the World Bank, the United Nations Development Program (UNDP) and the United Nations Environment Program (UNEP).

The Kyoto Protocol motivates us to study the efficiency properties of an interregional policy scheme which features both resource transfers and trading of carbon dioxide emissions. In doing so, we are also motivated by the USA's decision to not ratify the Kyoto Protocol, which occurred shortly after the Bush administration took office in 2001. Whether or not the USA's government was justified in "withdrawing" from the Kyoto Protocol is beyond the scope of this paper. We are mostly interested in investigating the potential implications for the allocation of resources in the global economy if all regions but one decide to participate in the interregional policy scheme. ${ }^{2}$

\footnotetext{
1 The call for emissions trading was, no doubt, motivated by the effectiveness of marketable permit programs in the USA (see, e.g., Hahn (1989) and Stavins (1998)). Furthermore, an impressive amount of research and experience underscores the benefits and costs associated with emissions trading programs (see, e.g., Maloney and Yandle (1984), Coggins and Swinton (1996) and references therein).

${ }^{2}$ We do explore the interesting issue of coalition formation in this paper. For good examples of papers that examine endogenous participation in international agreements, see Barrett (1994) and Black et. al (1993).
} 
We show that the equilibrium allocation for a global economy implied by an interregional policy scheme in which one region - the USA - does not participate is inefficient because resources are not transferred from or to the USA and the USA's government neglects the negative effects that its carbon dioxide emissions cause to the rest of the world. For a similar global economy, we also show that the equilibrium allocation implied by an interregional policy scheme which includes all regions in the globe -a scheme which we refer to as "Ideal Kyoto Protocol" - is Pareto efficient. The intuition for this important finding is simple and straightforward. The redistributive interregional transfer mechanism operated by an interregional agency - say, the GEF - makes every regional government realize that it is in its best interest to maximize global income. Every government knows, therefore, that its policy choice should internalize all externalities caused by its region's carbon dioxide emissions.

This paper is closely related to a set of game-theoretic papers that use sequential games to study provision of public goods (see, e.g., Arce (2001), Caplan et al. (2000) and Caplan and Silva (2002)). None of these papers, however, combines emissions trading and transfers. To our knowledge the only other article that features such a combination is Chichilnisky, et al. (2000). The authors demonstrate that equity and efficiency go hand in hand whenever carbon dioxide emissions are globally traded. In their framework, a market for emissions allocates resources efficiently if and only if international transfers are made in order to equalize social marginal utilities of consumption. They also show that this resource redistribution condition can be satisfied by an appropriate initial distribution of emission permits. Although our paper's message is fully consistent with theirs, our approach differs from theirs in two crucial ways in what respects the resource redistribution: (1) it is endogenous; and, more importantly, (2) it takes place after the regional governments choose their most desired emission quotas. It is the anticipation of the interregional resource transfers implemented by the GEF that makes the regional governments behave efficiently.

The paper is organized as follows. Section 2 builds the basic model. Section 3 characterizes a Pareto efficient allocation. Section 4 examines regional and interregional policy schemes. In subsection 4.1, we consider a policy setting in which regional governments, acting independently, simultaneously determine their environmental policy agendas. We characterize the equilibrium allocation of resources for the global economy in this arrangement and then demonstrate that it is inefficient. Next, we investigate two interregional policy regimes. Motivated by the USA's decision to withdraw from the Kyoto Protocol, in 
subsection 4.2 we consider a policy scheme in which all regions but one in the globe participate in it. The USA is excluded from both interregional emissions trading and transfer mechanisms, but it is able to announce - i.e., commit to - a regional policy scheme before the other regions make their own policy commitments under the Protocol. In the policy scheme of subsection 4.3, all regions participate in both mechanisms and make their policy commitments simultaneously. In both interregional policy settings, the GEF implements transfers after it observes the policy commitments of all regions. Section 5 concludes the paper.

\section{Basic Model}

Imagine a global economy consisting of $\mathrm{J}$ politically autonomous regions and governments, indexed by $\mathrm{j}, \mathrm{j}$ $=1, \ldots, \mathrm{J}$. There are two globally traded consumption commodities, a commodity whose production generates emissions of carbon dioxide (e.g., an industrial good) and a commodity whose production is harmed by emissions of carbon dioxide (e.g., an agricultural good). Let $Y_{j}$ be region j's industrial product and $\mathrm{E}$ be the global quantity of carbon dioxide emitted in the atmosphere. We assume that $\mathrm{E} \equiv \sum_{\mathrm{j}=1}^{\mathrm{J}} \mathrm{Y}_{\mathrm{j}}$; that is, production of a unit of the industrial good leads to the emission of a unit of carbon dioxide.

The industrial sector in region $\mathrm{j}$ is competitive and consists of a large number of identical producers. Let $I_{j}$ be the (fixed) number of industrial producers in region $j$. Each industrial producer utilizes an input quantity $\bar{x}_{j} \leq 0$ of the agricultural good to produce $\mathrm{f}^{\mathrm{j}}\left(\overline{\mathrm{x}}_{\mathrm{j}}\right)$ units of the industrial good. We assume that $\mathrm{f}^{\mathrm{j}}$ is decreasing and strictly concave. ${ }^{3}$ Define $\bar{X}_{\mathrm{j}} \equiv \mathrm{I}_{\mathrm{j}} \overline{\mathrm{X}}_{\mathrm{j}}$ as the total amount of the agricultural good demanded as input by region $\mathrm{j}$ 's industrial sector and $\mathrm{F}^{\mathrm{j}}\left(\overline{\mathrm{X}}_{\mathrm{j}}\right) \equiv \mathrm{I}_{\mathrm{j}} \mathrm{f}^{\mathrm{j}}\left(\overline{\mathrm{X}}_{\mathrm{j}} / \mathrm{I}_{\mathrm{j}}\right)$ as this sector's production function. Hence, $\mathrm{Y}_{\mathrm{j}}=\mathrm{F}^{\mathrm{j}}\left(\overline{\mathrm{X}}_{\mathrm{j}}\right)$. If we let $\mathrm{p}_{\mathrm{X}}$ and $\mathrm{p}_{\mathrm{Y}}$ denote the prices of the agricultural and industrial goods, respectively, the profit of the industrial sector in region $j$ is $p_{Y} Y_{j}+p_{x} \bar{X}_{j}$.

The agricultural sector in region $j$ is also competitive. Let $A_{j}$ be region $j$ 's (fixed) number of agricultural producers. Each agricultural producer utilizes an input quantity $\bar{y}_{j} \leq 0$ of the industrial good to produce $g^{j}\left(\bar{y}_{j}, E\right)$ units of the agricultural good. We assume that $g^{j}$ is decreasing in both arguments and

\footnotetext{
${ }^{3}$ Throughout the analysis, we use superscripts to index functions.
} 
strictly concave. Let $\bar{Y}_{j} \equiv A_{j} \bar{y}_{j}$ and $G^{j}\left(\bar{Y}_{j}, \sum_{i=1}^{j} F^{i}\left(\bar{X}_{i}\right)\right) \equiv A_{j} g^{j}\left(\bar{Y}_{j} / A_{j}, \sum_{i=1}^{j} F^{i}\left(\bar{X}_{i}\right)\right)$. Hence, region $j$ 's agricultural product is $X_{j}=G^{j}\left(\bar{Y}_{j}, \sum_{i=1}^{J} F^{i}\left(\bar{X}_{i}\right)\right)$ and its profit is $p_{X} X_{j}+p_{Y} \bar{Y}_{j}$.

Region $\mathrm{j}$ is populated by $\mathrm{n}_{\mathrm{j}}$ immobile consumers. Consumers within each region are identical in that they possess identical preferences and incomes. Let $U^{j}\left(x_{j}, y_{j}\right)$ be the utility function of a consumer in region $j$ who consumes $x_{j}$ units of the agricultural good and $y_{j}$ units of the industrial good. ${ }^{4}$ This function is assumed to be increasing in both arguments, quasiconcave and twice continuously differentiable.

Both industrial and agricultural goods are freely traded in global markets. Let $\mathrm{X}_{\mathrm{j}}^{0}$ and $\mathrm{Y}_{\mathrm{j}}^{0}$ denote region j's initial endowments of agricultural and industrial goods, respectively. In any equilibrium for the global economy, $\sum_{j=1}^{j}\left(n_{j} x_{j}-X_{j}^{0}-X_{j}-\bar{X}_{j}\right)=0$ and $\sum_{j=1}^{J}\left(n_{j} y_{j}-Y_{j}^{0}-Y_{j}-\bar{Y}_{j}\right)=0$; namely, the global markets must clear. To keep things simple, we henceforth normalize the price of the agricultural good to one. This normalization will enable us to ignore the market clearing condition for the agricultural good, since it is automatically satisfied whenever the other conditions that characterize an equilibrium allocation are satisfied. The normalization also allows us to set $\mathrm{p}_{\mathrm{Y}} \equiv \mathrm{p}$.

\section{Pareto Efficiency}

Before we examine regional and interregional environmental policy making, it is useful to derive the set of Pareto efficiency conditions for our economy. A Pareto efficient allocation can be obtained as follows. Choose $\left\{\mathrm{x}_{\mathrm{j}}, \mathrm{y}_{\mathrm{j}}, \mathrm{X}_{\mathrm{j}}, \mathrm{Y}_{\mathrm{j}}, \overline{\mathrm{X}}_{\mathrm{j}}, \overline{\mathrm{Y}}_{\mathrm{j}}\right\}_{\mathrm{j}=1, \ldots, \mathrm{J}}$ to maximize $\mathrm{U}^{1}\left(\mathrm{x}_{1}, \mathrm{y}_{1}\right)$ subject to $\mathrm{U}^{\mathrm{k}}\left(\mathrm{x}_{\mathrm{k}}, \mathrm{y}_{\mathrm{k}}\right) \geq \hat{U}^{\mathrm{k}}, \mathrm{k}=2, \ldots, \mathrm{J}$, $Y_{j} \leq F^{j}\left(\bar{X}_{j}\right), \quad X_{j} \leq G^{j}\left(\bar{Y}_{j}, \sum_{i=1}^{j} F^{i}\left(\bar{X}_{i}\right)\right), \quad \sum_{i=1}^{J}\left(n_{i} x_{i}-X_{i}^{0}-X_{i}-\bar{X}_{i}\right) \leq 0, \quad \sum_{i=1}^{J}\left(n_{i} y_{i}-Y_{i}^{0}-Y_{i}-\bar{Y}_{i}\right) \leq 0$, $x_{j} \geq 0, y_{j} \geq 0, X_{j} \geq 0, Y_{j} \geq 0, \bar{X}_{j} \leq 0, \bar{Y}_{j} \leq 0, j=1, \ldots, J$. An interior solution satisfies:

$$
\mathrm{U}^{\mathrm{k}}\left(\mathrm{x}_{\mathrm{k}}, \mathrm{y}_{\mathrm{k}}\right)=\hat{\mathrm{U}}^{\mathrm{k}}, \quad \mathrm{k}=2, \ldots, \mathrm{J},
$$

\footnotetext{
${ }^{4}$ For expositional ease, we assume that utility does not depend directly on E. It can be shown that, for a large family of utility functions, the results of our analysis would remain qualitatively the same if $E$ entered as an arguments in the utility function. A proof of this claim is available from the authors upon request.
} 


$$
\begin{aligned}
& Y_{j}=F^{j}\left(\bar{X}_{j}\right)>0, X_{j}=G^{j}\left(\bar{Y}_{j}, \sum_{i=1}^{J} F^{i}\left(\bar{X}_{i}\right)\right)>0, \quad j=1, \ldots, J, \\
& \sum_{i=1}^{J}\left(n_{i} x_{i}-X_{i}^{0}-X_{i}-\bar{X}_{i}\right)=0, \sum_{i=1}^{J}\left(n_{i} y_{i}-Y_{i}^{0}-Y_{i}-\bar{Y}_{i}\right)=0, \\
& \frac{U_{y}^{1}}{U_{x}^{1}}=\frac{U_{y}^{k}}{U_{x}^{k}}, \quad k=2, \ldots, J, \\
& \frac{U_{y}^{j}}{U_{x}^{j}}=-G_{Y}^{j}, \quad j=1, \ldots, J, \\
& G_{Y}^{j}=\frac{1}{F_{X}^{j}}+\sum_{i=1}^{j} G_{E}^{i}, \quad j=1, \ldots, J .
\end{aligned}
$$

Equations (1a) state that the utility constraints bind. Each region k reaches the exogenously given level of per capita welfare, $\hat{U}^{\mathrm{k}}$. Equations (1b) tell us that each region produces positive quantities of both commodities. Equations (1c) inform us that resources are fully employed. Equations (1d) state that individual marginal rates of substitution between industrial and agricultural goods must be equal across regions. Equations (1e) tell us that in each region the individual marginal rate of substitution between industrial and agricultural goods must be equal to the marginal rate of transformation for the agricultural good. Equations (1f) inform us that in each region the marginal rate of transformation for the agricultural good must be equal to the marginal rate of transformation for the industrial good. The marginal rate of transformation for the industrial good in each region includes the negative production effects brought about by global emissions of carbon dioxide.

For future reference, it is worth noting that Pareto efficiency requires satisfaction of three important conditions. First, marginal agricultural products must be equalized across regions:

$$
\mathrm{G}_{\mathrm{Y}}^{1}=\mathrm{G}_{\mathrm{Y}}^{\mathrm{k}}, \quad \mathrm{k}=2, \ldots, \mathrm{J} .
$$

Second, marginal industrial products must also be equalized across regions:

$$
\mathrm{F}_{\mathrm{x}}^{1}=\mathrm{F}_{\mathrm{X}}^{\mathrm{k}}, \quad \mathrm{k}=2, \ldots, \mathrm{J}
$$

Third, there must be interregional resource transfers. To see this, observe that we obtain the Pareto efficiency conditions (1a) - (1f) if and only if:

$$
\frac{\mathrm{U}_{\mathrm{x}}^{1}}{\mathrm{n}_{1}}=\mu=\frac{\lambda_{\mathrm{k}} \mathrm{U}_{\mathrm{x}}^{\mathrm{k}}}{\mathrm{n}_{\mathrm{k}}}, \quad \mathrm{k}=2, \ldots, \mathrm{J}
$$


where $\mu$ is the Lagrangian multiplier associated with the resource feasibility constraint for the agricultural commodity and $\lambda_{\mathrm{k}}$ is the Lagrangian multiplier associated with the utility constraint for region $\mathrm{k}$. Equations (2c) tell us how the agriculture commodity (our numeraire) should be allocated across regions. One unit of the numeraire good transferred to region 1 from some region k, increases region 1's per capita utility by an amount $U_{x}^{1} / n_{1}$, since the extra unit is shared by $n_{1}$ residents. Per capita utility in region $k$ is decreased by $\lambda_{k} U_{x}^{k} / n_{k}$, since $\lambda_{k}$ is the shadow cost of the utility constraint and the unit shortfall is shared by $\mathrm{n}_{\mathrm{k}}$ residents. Hence, equations (2c) inform us that interregional transfers of the numeraire good are implemented up to the point where the marginal shadow transfer benefit (of each recipient region) equates the marginal shadow transfer cost (of each remitter region).

\section{Regional and Interregional Policy Making}

We start our analysis of regional and interregional policy making by considering a situation in which all regions independently decide how to control their emissions of carbon dioxide. We call this regime "Regional Environmental Policy Making." We later study two interregional policy schemes, denoted "Ideal Kyoto Protocol" and "Kyoto Protocol without the USA." All regions in the globe participate in the "Ideal Kyoto Protocol." This is a scenario which apparently accords well with the Kyoto Protocol envisioned by its founders. All regions, except the USA, participate in the other interregional policy scheme, "Kyoto Protocol without the USA." This setting corresponds to a fairly optimistic view of the current situation, whereby all regions in the world, except the USA, will decide to participate. We do not consider other possible interregional policy schemes, characterized by fewer participating regions, because it does not seem likely that the Kyoto Protocol will survive if another country withdraws. ${ }^{5}$ It is not unreasonable to assume that yet another defection will trigger a chain of defections, which will eventually completely undermine the Protocol.

\footnotetext{
${ }^{5}$ At this stage, the Kyoto Protocol can be implemented only if most of the 33 Annex I countries that remain decide to participate in it. A requirement for the Protocol to be enacted is that the set of participating countries contains countries that accounted for a share greater or equal to $55 \%$ of the total carbon dioxide emitted by the original 34 Annex I countries in 1990. The participation rates of the USA, Russia, Japan and Germany in the total emissions of Annex I countries in 1990 were $36.1 \%, 17.4 \%, 8.5 \%$ and $7.4 \%$, respectively. If, in addition to the USA, Russia decides to withdraw, the Protocol will necessarily fail. If either Japan or Germany follows the USA's lead, the Protocol will not necessarily fail, but its chance of survival will be slim. Although defection of any other Annex I country will not be as harmful in a first instance, it is likely that it will eventually invite others to defect, undermining the Protocol's viability.
} 


\subsection{Regional Environmental Policy Making}

Suppose that there is a separate market for emission permits within each region. This will facilitate comparison with the subsequent arrangements. The regional government in region $\mathrm{j}$ - henceforth called "regulator $j$ " - sets a quota, $Q_{j}$, of emission permits that can be sold. Regulator $j$ endows each consumer in the region with $q_{j} \equiv Q_{j} / n_{j}$ emission permits. Since consumption activities do not emit carbon dioxide, consumers are sellers in each regional market for emission permits. Every industrial producer in region $\mathrm{j}$ must purchase at a cost $c_{j} \geq 0$ an emission permit per unit of the industrial good he produces.

The representative consumer in region j sells $s_{j}$ emission permits, $0 \leq s_{j} \leq q_{j}$, and earn $c_{j} s_{j}$ units of income. Hence, his budget constraint is

$$
x_{j}+p y_{j}=c_{j} s_{j}+\frac{X_{j}^{0}+p Y_{j}^{0}+\Pi_{j}}{n_{j}},
$$

where $\Pi_{\mathrm{j}}$ corresponds to the sum of industry's and agriculture's regional profits. This consumer chooses nonnegative quantities $\left\{\mathrm{x}_{\mathrm{j}}, \mathrm{y}_{\mathrm{j}}, \mathrm{s}_{\mathrm{j}}\right\}$ to maximize $\mathrm{U}^{\mathrm{j}}\left(\mathrm{x}_{\mathrm{j}}, \mathrm{y}_{\mathrm{j}}\right)$ subject to both his budget constraint and $\mathrm{s}_{\mathrm{j}} \leq \mathrm{q}_{\mathrm{j}}$, taking $p, c_{j}$ and $\left\{X_{j}^{0}+p Y_{j}^{0}+\Pi_{j}\right\} / n_{j}$ as given. First, note that it is optimal for this consumer to sell $q_{j}$ pollution permits. Setting $s_{j}=q_{j}$, the budget constraint becomes

$$
x_{j}+p y_{j}=c_{j} q_{j}+\frac{X_{j}^{0}+p Y_{j}^{0}+\Pi_{j}}{n_{j}} .
$$

Assuming that the consumer finds it optimal to consume strictly positive amounts of both agriculture and industrial commodities, the solution to his problem satisfies (3a) and the following tangency condition:

$$
\frac{U_{y}^{j}}{U_{x}^{j}}=p
$$

Equation (3b) demonstrates that in each region the representative individual's marginal rate of substitution between industrial and agricultural goods must be equal to the (relative) price of the industrial good. Let $\mathrm{m}_{\mathrm{j}} \equiv \mathrm{c}_{\mathrm{j}} \mathrm{q}_{\mathrm{j}}+\left\{\mathrm{X}_{\mathrm{j}}^{0}+\mathrm{pY} \mathrm{j}_{\mathrm{j}}^{0}+\Pi_{\mathrm{j}}\right\} / \mathrm{n}_{\mathrm{j}}$. We can now use equations (3) to implicitly define the demand functions of the representative individual in region $\mathrm{j}, \mathrm{x}^{\mathrm{j}}\left(\mathrm{p}, \mathrm{m}_{\mathrm{j}}\right)$ and $\mathrm{y}^{\mathrm{j}}\left(\mathrm{p}, \mathrm{m}_{\mathrm{j}}\right)$. 
The industrial sector in region $\mathrm{j}$ chooses $\left\{\overline{\mathrm{X}}_{\mathrm{j}}\right\}$ to maximize $\left(\mathrm{p}-\mathrm{c}_{\mathrm{j}}\right) \mathrm{F}^{\mathrm{j}}\left(\overline{\mathrm{X}}_{\mathrm{j}}\right)+\overline{\mathrm{X}}_{\mathrm{j}}$ subject to $\overline{\mathrm{X}}_{\mathrm{j}} \leq 0$, taking $\mathrm{p}$ and $\mathrm{c}_{\mathrm{j}}$ as given. Assuming that $\mathrm{p}>\mathrm{c}_{\mathrm{j}}$, the industrial sector of each region maximizes profit if and only if

$$
-\left(p-c_{j}\right) F_{x}^{j}=1, \quad j=1, \ldots, J
$$

that is, the realized value of the regional marginal industrial product (left side) must be equal to the regional marginal input cost (right side). Let $r_{j} \equiv p-c_{j}$ denote the price of the industrial good net of the marginal regulatory cost, $c_{j}$. Equations $(4 a)$ enables us to implicitly define the input demand functions $\bar{X}^{j}\left(r_{j}\right)$, $\mathrm{j}=1, \ldots, \mathrm{J}$. Hence, the industrial sectors' supply functions are $\mathrm{Y}^{\mathrm{j}}\left(\mathrm{r}_{\mathrm{j}}\right) \equiv \mathrm{F}^{\mathrm{j}}\left(\overline{\mathrm{X}}^{\mathrm{j}}\left(\mathrm{r}_{\mathrm{j}}\right)\right), \mathrm{j}=1, \ldots, \mathrm{J}$.

The agricultural sector in region $j$ chooses $\left\{\bar{Y}_{j}\right\}$ to maximize $G^{j}\left(\bar{Y}_{j}, E\right)+p \bar{Y}_{j}$ subject to $\bar{Y}_{j} \leq 0$, taking $\mathrm{p}$ and $\mathrm{E}$ as given. The agricultural sector of each region maximizes profit if and only if

$$
-\mathrm{G}_{\mathrm{Y}}^{\mathrm{j}}=\mathrm{p}, \quad \mathrm{j}=1, \ldots, \mathrm{J},
$$

that is, the regional marginal agricultural product must be equal to the regional marginal input cost. Equations (4b) enable us to implicitly define the input demand functions $\bar{Y}^{j}(p, E), j=1, \ldots ., J$. Then, the agricultural sectors' supply functions are $X^{j}(p, E) \equiv G^{j}\left(\bar{Y}^{j}(p, E), E\right), j=1, \ldots, J$.

Given $r_{j}$, the industrial sector in region $j$ demands $Y^{j}\left(r_{j}\right)$ emission permits. Then, the regional market for permits clears if and only if

$$
Y^{j}\left(r_{j}\right)=Q_{j}
$$

Since $r_{j} \equiv p-c_{j}$, we can use equation (5a) to implicitly define $c^{j}\left(p, Q_{j}\right)$. It follows that $c_{Q}^{j}=-1 / Y_{r}^{j}<0$, where $c_{Q}^{j} \equiv \partial c^{j} / \partial Q_{j}$ and $Y_{r}^{j} \equiv d Y^{j} / d r_{j}$. Since, in equilibrium, equation (5a) holds for each $j$, we have

$$
Y^{j}\left(p-c^{j}\left(p, Q_{j}\right)\right)=Q_{j}, \quad j=1, \ldots, J
$$

We now turn our attention to the problems facing regional regulators. First, we need to compute regional per capita incomes and then later derive the indirect utility functions of the regional representative individuals. Each regulator chooses a quota level of regional permits that maximizes the utility of his region's representative consumer. 
Given equations $(5 b)$, we can write the total profits of the industrial and agricultural sectors in region j, as $\left(p-c^{j}\left(p, Q_{j}\right)\right) Y^{j}\left(p-c^{j}\left(p, Q_{j}\right)\right)+\bar{X}^{j}\left(p-c^{j}\left(p, Q_{j}\right)\right) \quad$ and $\quad X^{j}\left(p, \sum_{i=1}^{j} Q_{i}\right)+p \bar{Y}^{j}\left(p, \sum_{i=1}^{j} Q_{i}\right)$, respectively. Note that equations (5b) imply that $E=\sum_{j=1}^{J} Q_{j}$. Let $Q \equiv \sum_{j=1}^{J} Q_{j}$. Adding up the profits of both sectors, we have $\Pi^{\mathrm{j}}\left(\mathrm{p}, \mathrm{Q}_{\mathrm{j}}, \mathrm{Q}\right) \equiv\left\{\left(\mathrm{p}-\mathrm{c}^{\mathrm{j}}\left(\mathrm{p}, \mathrm{Q}_{\mathrm{j}}\right)\right) \mathrm{Y}^{\mathrm{j}}\left(\mathrm{p}-\mathrm{c}^{\mathrm{j}}\left(\mathrm{p}, \mathrm{Q}_{\mathrm{j}}\right)\right)+\bar{X}^{\mathrm{j}}\left(\mathrm{p}-\mathrm{c}^{\mathrm{j}}\left(\mathrm{p}, \mathrm{Q}_{\mathrm{j}}\right)\right)\right\}+\left\{X^{\mathrm{j}}(\mathrm{p}, \mathrm{Q})+\mathrm{p} \bar{Y}^{\mathrm{j}}(\mathrm{p}, \mathrm{Q})\right\}$. This enables us to write regional per capita income as a function of $p, Q_{j}$ and $Q$ as follows:

$$
m^{j}\left(p, Q_{j}, Q\right) \equiv \frac{X_{j}^{0}+p Y_{j}^{0}+\Pi^{j}\left(p, Q_{j}, Q\right)+c^{j}\left(p, Q_{j}\right) Q_{j}}{n_{j}}
$$

Regulator $j$ chooses $\left\{Q_{j}\right\}$ to maximize $\left.V^{\mathrm{j}}\left(p, Q_{j}, Q\right) \equiv U^{\mathrm{j}}\left(x^{\mathrm{j}}\left(p, m^{\mathrm{j}}\left(p, Q_{j}, Q\right)\right)\right) \mathrm{y}^{\mathrm{j}}\left(\mathrm{p}, \mathrm{m}^{\mathrm{j}}\left(\mathrm{p}, \mathrm{Q}_{\mathrm{j}}, \mathrm{Q}\right)\right)\right)$ subject to: (6), $Q=Q_{j}+\sum_{k \neq j}^{J} Q_{k}$ and $Q_{j} \geq 0$, taking $p$ and $Q_{k}, \forall k \neq j$, as given. Assuming an interior solution, the first order condition for maximization of $V^{j}\left(p, Q_{j}, Q\right)$ is

$$
\frac{d V^{j}\left(p, Q_{j}, Q\right)}{d Q_{j}}=\left\{U_{x}^{j} X_{m}^{j}+U_{y}^{j} y_{m}^{j}\right\} \frac{d m^{j}\left(p, Q_{j}, Q\right)}{d Q_{j}}=0 .
$$

Since the solution to the utility maximization problem for the representative individual implies that

$$
x_{m}^{j}+\frac{U_{y}^{j}}{U_{x}^{j}} y_{m}^{j}=x_{m}^{j}+p y_{m}^{j}=1,
$$

the second equation in (7a) can be rewritten as

$$
\frac{\mathrm{dm}^{\mathrm{j}}\left(\mathrm{p}, \mathrm{Q}_{\mathrm{j}}, \mathrm{Q}\right)}{\mathrm{dQ}}=0
$$

Equation (7b) clearly shows that each regulator seeks to maximize regional per capita income. From equation (6), we obtain:

$$
\frac{d m^{j}\left(p, Q_{j}, Q\right)}{d Q_{j}}=\frac{1}{n_{j}}\left\{-\left(r_{j} F_{X}^{j}+1\right)\left(\bar{X}_{r}^{j} c_{Q}^{j}\right)-Y^{j} c_{Q}^{j}+\left(G_{Y}^{j}+p\right)\left(\bar{Y}_{E}^{j}\right)+G_{E}^{j}+Q_{j} c_{Q}^{j}+c^{j}\right\}=0 .
$$

Given equations (4a), (4b) and (5a), equation (7c) reduces to

$$
c^{j}\left(p, Q_{j}\right)+G_{E}^{j}\left(\bar{Y}^{j}(p, Q), Q\right)=0
$$

Differentiating the first order condition (7d) with respect to $Q_{j}$ yields 


$$
c_{Q}^{j}+G_{E Y}^{j} \bar{Y}_{E}^{j}+G_{E E}^{j} \equiv c_{Q}^{j}-\frac{\left(G_{E Y}^{j}\right)^{2}}{G_{Y Y}^{j}}+G_{E E}^{j} \equiv c_{Q}^{j}+\frac{G_{Y Y}^{j} G_{E E}^{j}-\left(G_{E Y}^{j}\right)^{2}}{G_{Y Y}^{j}}<0 .
$$

The sign of the second order condition (7e) follows from strict concavity of $G^{j}$ and the fact that $c_{Q}^{j}<0$. Hence, the per capita income function (6) is strictly concave and the first order condition (7d) is not only necessary but also sufficient for an interior maximum.

Assuming that equation (7d) holds for all $\mathrm{j}$ in the Nash equilibrium, we obtain:

$$
\mathrm{c}^{\mathrm{j}}\left(\mathrm{p}, \mathrm{Q}_{\mathrm{j}}\right)=-\mathrm{G}_{\mathrm{E}}^{\mathrm{j}}\left(\overline{\mathrm{Y}}^{\mathrm{j}}(\mathrm{p}, \mathrm{Q}), \mathrm{Q}\right), \quad \mathrm{j}=1, \ldots, \mathrm{J} .
$$

Equations (8) inform us that each regulator finds it optimal to supply emission permits at the level in which the regional price of the permit equals the regional marginal damage caused by carbon dioxide emissions. Equations (8) also clearly demonstrate that in equilibrium regional supplies of emission permits become functions of $p$. Let $Q^{j}(p)$ and $Q(p) \equiv \sum_{i=1}^{J} Q^{i}(p)$ denote the quota functions for region $j$ and the globe as a whole. Now define $\mathrm{m}^{\mathrm{j}}(\mathrm{p}) \equiv \mathrm{m}^{\mathrm{j}}\left(\mathrm{p}, \mathrm{Q}^{\mathrm{j}}(\mathrm{p}), \mathrm{Q}(\mathrm{p})\right), \mathrm{y}^{\mathrm{j}}(\mathrm{p}) \equiv \mathrm{y}^{\mathrm{j}}\left(\mathrm{p}, \mathrm{m}^{\mathrm{j}}(\mathrm{p})\right), \mathrm{r}^{\mathrm{j}}(\mathrm{p}) \equiv \mathrm{p}-\mathrm{c}^{\mathrm{j}}\left(\mathrm{p}, \mathrm{Q}^{\mathrm{j}}(\mathrm{p})\right)$ and $\overline{\mathrm{Y}}^{\mathrm{j}}(\mathrm{p}) \equiv \overline{\mathrm{Y}}^{\mathrm{j}}(\mathrm{p}, \mathrm{Q}(\mathrm{p}))$. Given these definitions, we may write the market clearing condition for the industrial good as follows:

$$
\sum_{j=1}^{j}\left(n_{j} y^{j}(p)-Y_{j}^{0}-Y^{j}\left(r^{j}(p)\right)-\bar{Y}^{j}(p)\right)=0
$$

The price of the industrial good, $p$, is determined endogenously by equation (9).

In this setting, the equilibrium allocation for the global economy is given by conditions (3a), (3b), (4a), (4b), (5b), (8) and (9). Comparing these conditions with the Pareto efficiency conditions immediately reveals that regional policy making is inefficient. There are two sources of inefficiency: (1) the absence of interregional income transfers, since regional marginal shadow utilities of income are not necessarily equalized; and (2) the presence of interregional external effects associated with regional production of the industrial commodity, since every regulator neglects the negative effects that production of the industrial commodity in his region cause to every other region in the globe.

For future reference, let $\mathrm{V}^{\mathrm{jD}}$ denote region $\mathrm{j}$ 's per capita utility level realized in the global equilibrium allocation described above. 


\subsection{Kyoto Protocol without the USA}

Suppose that all regions in the globe, except for the USA, participate in an interregional policy scheme denoted "KP-USA" for notational simplicity - in which an interregional market for carbon dioxide emissions coexists with an interregional transfer mechanism. Motivated by current events, we postulate that the USA commits to an environmental policy before the KP-USA regions commit to their own environmental policies. In addition, the Global Environmental Facility (GEF) is only able to implement interregional transfers after it observes the policy choices of the KP-USA regions. Hence, it seems natural to model the game played by the USA, the KP-USA regions and the GEF as a three-stage game. The USA chooses its environmental policy in the first stage of the game. The KP-USA regions observe the USA's policy choice and simultaneously choose their own policies in the second stage of the game. Finally, in the third stage, the GEF, having already observed the policy choices of all regions, implements interregional income transfers across the KP-USA regions. The equilibrium concept for the game is subgame perfection.

Before we analyze the three-stage policy game described above, let us examine how consumers and regional industrial and agricultural sectors behave in this regime. Let the USA be region 1 and $\mathrm{m}_{1}$ denote its per capita income. The representative consumer's demand functions are $\mathrm{x}^{1}\left(\mathrm{p}, \mathrm{m}_{1}\right)$ and $\mathrm{y}^{1}\left(\mathrm{p}, \mathrm{m}_{1}\right)$. This consumer's indirect utility function is $\mathrm{V}^{1}\left(\mathrm{p}, \mathrm{m}_{1}\right) \equiv \mathrm{U}^{1}\left(\mathrm{x}^{1}\left(\mathrm{p}, \mathrm{m}_{1}\right), \mathrm{y}^{1}\left(\mathrm{p}, \mathrm{m}_{1}\right)\right)$.

As for the KP-USA regions, the GEF redistributes per capita incomes through its interregional transfer mechanism. Let $T_{k}$ denote the quantity of income (in terms of the agricultural good) the GEF transfers to region $\mathrm{k}$, if positive, or receives from region $\mathrm{k}$, if negative. Interpreting $\mathrm{m}_{\mathrm{k}}$ as before, let $\mathrm{w}_{\mathrm{k}} \equiv \mathrm{m}_{\mathrm{k}}+\mathrm{T}_{\mathrm{k}} / \mathrm{n}_{\mathrm{k}}$ denote per capita income in region $\mathrm{k}$ after the income transfer is made. The

representative consumer's demand functions are $x^{k}\left(p, w_{k}\right)$ and $y^{k}\left(p, w_{k}\right)$. This consumer's indirect utility function is $\mathrm{V}^{\mathrm{k}}\left(\mathrm{p}, \mathrm{w}_{\mathrm{k}}\right) \equiv \mathrm{U}^{\mathrm{k}}\left(\mathrm{x}^{\mathrm{k}}\left(\mathrm{p}, \mathrm{w}_{\mathrm{k}}\right), \mathrm{y}^{\mathrm{k}}\left(\mathrm{p}, \mathrm{w}_{\mathrm{k}}\right)\right)$.

Letting $\mathrm{c}_{1}$ denote the price of a permit in the USA and assuming that $\mathrm{p}>\mathrm{c}_{1}$, the industrial sector in the USA maximizes profit if and only if

$$
-\left(\mathrm{p}-\mathrm{c}_{1}\right) \mathrm{F}_{\mathrm{x}}^{1}=1
$$

Let $r_{1} \equiv p-c_{1}$. This industry's input demand and supply functions are $\bar{X}^{1}\left(r_{1}\right)$ and $Y^{1}\left(r_{1}\right)$, respectively. 
Consider now the industrial sector in region $\mathrm{k}$. Let $\mathrm{c}_{\mathrm{O}}$ denote the price of an emission permit in the interregional market for permits. The problem faced by the industrial sector in region $\mathrm{k}$ is the same as in the regional policy making regime, except that now the price of a permit is $c_{o}$ rather than $c_{k}$. Assuming that $\mathrm{p}>\mathrm{c}_{\mathrm{O}}$, the industrial sector of each KP-USA region maximizes profit if and only if:

$$
-\left(\mathrm{p}-\mathrm{c}_{\mathrm{o}}\right) \mathrm{F}_{\mathrm{x}}^{\mathrm{k}}=1, \quad \mathrm{k}=2, \ldots, \mathrm{J}
$$

Let $r_{O} \equiv p-c_{O}$. The industries' input demand and supply functions are $\bar{X}^{k}\left(r_{O}\right)$ and $Y^{k}\left(r_{O}\right), k=2, \ldots, J$.

The problem faced by the agricultural sector in each region of the globe, including the USA, is the same as in the regional policy making regime. Hence, equations (4b) are the profit maximization conditions for the regional agriculture sectors and the sectors' input demand and supply functions are respectively $\bar{Y}^{j}(p, E)$ and $X^{j}(p, E), j=1, \ldots, J$.

The permit markets - in the USA and in the aggregate KP-USA region - clear if and only if

$$
\begin{aligned}
& \mathrm{Y}^{1}\left(\mathrm{r}_{1}\right)=\mathrm{Q}_{1} . \\
& \sum_{\mathrm{k}=2}^{\mathrm{J}} \mathrm{Y}^{\mathrm{k}}\left(\mathrm{r}_{\mathrm{O}}\right)=\sum_{\mathrm{k}=2}^{\mathrm{J}} \mathrm{Q}_{\mathrm{k}} .
\end{aligned}
$$

Given $\mathrm{p}$, equation (11a) enables us to define $\mathrm{c}^{1}\left(\mathrm{p}, \mathrm{Q}_{1}\right)$. Note that $\mathrm{c}_{\mathrm{Q}}^{1}=-1 / \mathrm{Y}_{\mathrm{r}}^{1}<0$. Let $\mathrm{Q}_{\Sigma} \equiv \sum_{\mathrm{k}=2}^{\mathrm{J}} \mathrm{Q}_{\mathrm{k}}$ denote the aggregate quota of emission permits supplied in the aggregate KP-USA region.. Then, given $\mathrm{p}$, equation $(11 b)$ can be used to define $c^{o}\left(p, Q_{\Sigma}\right)$. It is easy to verify that $c_{Q}^{o}=-1 / \sum_{k=2}^{J} Y_{r}^{k}<0$, where $\mathrm{c}_{\mathrm{Q}}^{\mathrm{O}} \equiv \partial \mathrm{c}^{\mathrm{o}} / \partial \mathrm{Q}_{\Sigma}$ and $\mathrm{Y}_{\mathrm{r}}^{\mathrm{h}} \equiv \mathrm{dY^{ \textrm {h } }} / \mathrm{dr}_{\mathrm{O}}$

Regional profits in the USA and in each region $\mathrm{k}, \mathrm{k}=2, \ldots, \mathrm{J}$, are as follows:

$$
\begin{gathered}
\Pi^{1}\left(p, Q_{1}, Q\right) \equiv\left\{\left(p-c^{1}\left(p, Q_{1}\right)\right) Y^{1}\left(p-c^{1}\left(p, Q_{1}\right)\right)+\bar{X}^{1}\left(p-c^{1}\left(p, Q_{1}\right)\right)\right\}+\left\{X^{1}(p, Q)+p \bar{Y}^{1}(p, Q)\right\}, \\
\Pi^{k}\left(p, Q_{\Sigma}, Q\right) \equiv\left\{\left(p-c^{o}\left(p, Q_{\Sigma}\right)\right) Y^{k}\left(p-c^{o}\left(p, Q_{\Sigma}\right)\right)+\bar{X}^{k}\left(p-c^{o}\left(p, Q_{\Sigma}\right)\right)\right\}+\left\{X^{k}(p, Q)+p \bar{Y}^{k}(p, Q)\right\} .
\end{gathered}
$$

We are now ready to examine the three-stage policy game. Let us assume that the GEF's objective function is a weighted sum of regional per capita (indirect) utilities $F\left(V^{2}, \ldots, V^{\mathrm{J}}\right) \equiv \sum_{\mathrm{k}=2}^{\mathrm{J}} \theta_{\mathrm{k}} \mathrm{V}^{\mathrm{k}}$, where $\theta_{\mathrm{k}}>0$ 
for every k and $\sum_{k=2}^{J} \theta_{k} \equiv 1$. The weights are exogenously given. We postulate that they are implied by the equilibrium of a political bargaining game, which takes place before the regions commit to participating in the KP-USA. We do not, however, attempt to formalize such a game here. This is an interesting avenue for future work.

Consider the third stage of the policy game. Given $\mathrm{p}, \mathbf{Q} \equiv\left(\mathrm{Q}_{1}, \ldots, \mathrm{Q}_{\mathrm{J}}\right)$ and $\mathbf{m} \equiv\left(\mathrm{m}_{1}, \ldots, \mathrm{m}_{\mathrm{J}}\right)$, the GEF chooses interregional income transfers $\left\{\mathrm{T}_{\mathrm{k}}\right\}_{\mathrm{k}=2, \ldots, \mathrm{J}}$ to maximize $\sum_{\mathrm{h}=2}^{J} \theta_{\mathrm{h}} \mathrm{V}^{\mathrm{h}}\left(\mathrm{p}, \mathrm{w}_{\mathrm{h}}\right)$ subject to $\mathrm{w}_{\mathrm{h}} \equiv \mathrm{m}_{\mathrm{h}}+\mathrm{T}_{\mathrm{h}} / \mathrm{n}_{\mathrm{h}}$ and $\sum_{\mathrm{h}=2}^{\mathrm{J}} \mathrm{T}_{\mathrm{h}}=0$. Let $\mathrm{W}_{\mathrm{k}} \equiv \mathrm{n}_{\mathrm{k}} \mathrm{w}_{\mathrm{k}}$ and $\mathrm{M}_{\mathrm{k}} \equiv \mathrm{n}_{\mathrm{k}} \mathrm{m}_{\mathrm{k}}, \mathrm{k}=2, \ldots, \mathrm{J}$. Given these definitions, the GEF's problem can be alternatively expressed as the choice of $\left\{\mathrm{W}_{\mathrm{k}}\right\}_{\mathrm{k}=2, \ldots, \mathrm{J}}$ to maximize $\sum_{k=1}^{J} \theta_{k} V^{k}\left(p, W_{k} / n_{k}\right)$ subject to $\sum_{k=2}^{J} W_{k}=\sum_{k=2}^{J} M_{k}$. The first order conditions for maximization can be written as follows:

$$
\begin{gathered}
\frac{\theta_{k} U_{x}^{k}\left(x^{k}\left(p, W_{k} / n_{k}\right), y^{k}\left(p, W_{k} / n_{k}\right)\right)}{n_{k}}=v, \quad k=2, \ldots, J, \\
\sum_{k=2}^{J} W_{k}=\sum_{k=2}^{J} M_{k},
\end{gathered}
$$

where $v>0$ is the Lagrangian multiplier associated with the feasibility constraint (12b). Equations (12a) tell us that the GEF redistributes income across the KP-USA regions in order to equate individuals' marginal utilities of income.

Let $\mathrm{M}_{\Sigma} \equiv \sum_{\mathrm{k}=2}^{\mathrm{J}} \mathrm{M}_{\mathrm{k}}$ denote the KP-USA's aggregate income level. Close inspection of equations (12a) and (12b) reveals that we can define regional incomes as functions of the price of the industrial good and the KP-USA's aggregate income level, $\mathrm{W}^{\mathrm{k}}\left(\mathrm{p}, \mathrm{M}_{\mathrm{\Sigma}}\right), \mathrm{k}=2, \ldots, \mathrm{J}$. Inserting these functions and $\mathrm{M}_{\Sigma}$ into equation (12b), we obtain

$$
\sum_{k=2}^{J} W^{k}\left(p, M_{\Sigma}\right)=M_{\Sigma}
$$

Differentiating equation (12c) with respect to $\mathrm{M}_{\Sigma}$ yields 


$$
\sum_{k=2}^{J} W_{M}^{k}=1
$$

where $\mathrm{W}_{\mathrm{M}}^{\mathrm{k}} \equiv \partial \mathrm{W}^{\mathrm{k}} / \partial \mathrm{M}_{\Sigma}$, for $\mathrm{k}=2, \ldots, \mathrm{J}$.

The KP-USA's aggregate income level is given by the sum of initial endowments and profits over all KP-USA regions. Hence,

$$
\mathrm{M}_{\Sigma}=\mathrm{c}^{\mathrm{o}}\left(\mathrm{p}, \mathrm{Q}_{\Sigma}\right) \mathrm{Q}_{\Sigma}+\sum_{\mathrm{h}=2}^{\mathrm{J}}\left(\mathrm{X}_{\mathrm{h}}^{0}+\mathrm{p} \mathrm{Y}_{\mathrm{h}}^{0}+\Pi^{\mathrm{h}}\left(\mathrm{p}, \mathrm{Q}_{\Sigma}, \mathrm{Q}\right)\right)
$$

where one should remember that $\mathrm{Q}_{\Sigma} \equiv \sum_{\mathrm{n}=2}^{\mathrm{J}} \mathrm{Q}_{\mathrm{h}}$.

In the second stage of the game, regulator $\mathrm{k}$ wishes to maximize $\mathrm{V}^{\mathrm{k}}\left(\mathrm{p}, \mathrm{W}^{\mathrm{k}}\left(\mathrm{p}, \mathrm{M}_{\Sigma}\right) / \mathrm{n}_{\mathrm{k}}\right)$. However, one can easily check that $\mathrm{V}^{\mathrm{k}}\left(\mathrm{p}, \mathrm{W}^{\mathrm{k}}\left(\mathrm{p}, \mathrm{M}_{\Sigma}\right) / \mathrm{n}_{\mathrm{k}}\right)$ is maximized if and only if regional income, $\mathrm{W}^{\mathrm{k}}\left(\mathrm{p}, \mathrm{M}_{\Sigma}\right)$, is maximized. This implies that regulator $k$ chooses nonnegative $\left\{Q_{k}\right\}$ to maximize $W^{k}\left(p, M_{\Sigma}\right)$ subject to equation (13) and $\mathrm{Q}_{\Sigma} \equiv \sum_{\mathrm{h}=2}^{\mathrm{J}} \mathrm{Q}_{\mathrm{h}}$, taking $\mathrm{p}$ and every other regulator's choice as given. Assuming that the solution of each regulator's problem is interior, the first order conditions that characterize the Nash equilibrium in the second stage of the game are

$$
\mathrm{W}_{\mathrm{M}}^{\mathrm{k}}\left(\mathrm{c}^{\mathrm{o}}+\sum_{\mathrm{n}=2}^{\mathrm{J}} \mathrm{G}_{\mathrm{E}}^{\mathrm{h}}\right)=0, \quad \mathrm{k}=2, \ldots, \mathrm{J}
$$

Given equation (12d), we obtain the following result when we add up the J-1 equations (14a):

$$
\left(c^{\mathrm{o}}+\sum_{\mathrm{n}=2}^{\mathrm{J}} \mathrm{G}_{\mathrm{E}}^{\mathrm{h}}\right) \sum_{\mathrm{k}=2}^{\mathrm{J}} \mathrm{W}_{\mathrm{M}}^{\mathrm{k}}=\left(\mathrm{c}^{\mathrm{o}}+\sum_{\mathrm{n}=2}^{\mathrm{J}} \mathrm{G}_{\mathrm{E}}^{\mathrm{h}}\right)=0,
$$

or

$$
\mathrm{c}^{\mathrm{o}}\left(\mathrm{p}, \mathrm{Q}_{\Sigma}\right)=-\sum_{\mathrm{h}=2}^{\mathrm{J}} \mathrm{G}_{\mathrm{E}}^{\mathrm{h}}\left(\overline{\mathrm{Y}}^{\mathrm{h}}(\mathrm{p}, \mathrm{Q}), \mathrm{Q}\right)
$$

Equation (14b) is the equilibrium condition that determines the KP-USA's aggregate quota level. It states that all regulators within the aggregate KP-USA region agree on a emission permit price equal to the sum of the marginal damages caused by carbon dioxide emissions to all KP-USA regions. As each regulator's maximization problem makes it clear, the transfers implemented by the GEF induce each regulator to choose a quota level which maximizes the KP-USA aggregate income level. Hence, each 
regulator has a strong incentive to internalize the externalities that production of the industrial good in his region causes to all other KP-USA regions.

Equation (14b) permits us to define the KP-USA's aggregate quota as a function of the quota of emission permits supplied by the USA and the price of the industrial good, namely, $Q^{\Sigma}\left(p, Q_{1}\right)$. Inserting this function into equation (14b), we have

$$
\mathrm{c}^{\mathrm{o}}\left(\mathrm{p}, \mathrm{Q}^{\Sigma}\left(\mathrm{Q}_{1}\right)\right)=-\sum_{\mathrm{k}=2}^{\mathrm{J}} \mathrm{G}_{\mathrm{E}}^{\mathrm{k}}\left(\overline{\mathrm{Y}}^{\mathrm{k}}\left(\mathrm{p}, \mathrm{Q}_{1}+\mathrm{Q}^{\Sigma}\left(\mathrm{Q}_{1}\right)\right), \mathrm{Q}_{1}+\mathrm{Q}^{\Sigma}\left(\mathrm{Q}_{1}\right)\right)
$$

Differentiating equation (15) with respect to $Q_{1}$ yields

$$
\frac{\mathrm{dQ}^{\Sigma}}{\mathrm{dQ}_{1}}=-\frac{\sum_{\mathrm{k}=2}^{\mathrm{J}}\left(\mathrm{G}_{\mathrm{YE}}^{\mathrm{k}} \overline{\mathrm{Y}}_{\mathrm{E}}^{\mathrm{k}}+\mathrm{G}_{\mathrm{EE}}^{\mathrm{k}}\right)}{\mathrm{c}_{\mathrm{Q}}^{\mathrm{o}}} \equiv-\frac{\sum_{\mathrm{k}=2}^{\mathrm{J}}\left(\frac{\mathrm{G}_{\mathrm{YY}}^{\mathrm{k}} \mathrm{G}_{\mathrm{EE}}^{\mathrm{k}}-\left(\mathrm{G}_{\mathrm{YE}}^{\mathrm{k}}\right)^{2}}{\mathrm{G}_{\mathrm{YY}}^{\mathrm{k}}}\right)}{\mathrm{c}_{\mathrm{Q}}^{\mathrm{o}}}<0 .
$$

Equation (16) demonstrates that an expansion in the USA's quota leads to a reduction in the KP-USA's aggregate quota.

In the first stage of the game, the regulator in the USA chooses nonnegative $\left\{\mathrm{Q}_{1}\right\}$ to maximize

$$
\mathrm{M}^{1}\left(\mathrm{p}, \mathrm{Q}_{1}\right) \equiv \mathrm{X}_{1}^{0}+\mathrm{p} \mathrm{Y}_{1}^{0}+\Pi^{1}\left(\mathrm{p}, \mathrm{Q}_{1}, \mathrm{Q}_{1}+\mathrm{Q}^{\Sigma}\left(\mathrm{Q}_{1}\right)\right)+\mathrm{c}^{1}\left(\mathrm{p}, \mathrm{Q}_{1}\right) \mathrm{Q}_{1} .
$$

Assuming an interior solution, the first order condition can be written as follows:

$$
\mathrm{c}^{1}\left(\mathrm{p}, \mathrm{Q}_{1}\right)=-\left(1+\frac{\mathrm{dQ}^{\Sigma}\left(\mathrm{p}, \mathrm{Q}_{1}\right)}{\mathrm{d} \mathrm{Q}_{1}}\right) \mathrm{G}_{\mathrm{E}}^{1}\left(\overline{\mathrm{Y}}^{1}\left(\mathrm{p}, \mathrm{Q}_{1}+\mathrm{Q}^{\Sigma}\left(\mathrm{p}, \mathrm{Q}_{1}\right)\right), \mathrm{Q}_{1}+\mathrm{Q}^{\Sigma}\left(\mathrm{p}, \mathrm{Q}_{1}\right)\right)
$$

where $\mathrm{dQ}^{\Sigma} / \mathrm{dQ}_{1}$ is given by equation (16). Equation (18) states that the USA's regulator chooses a quota level such that the USA's permit price equals the "perceived" marginal damage caused by carbon dioxide emissions in the USA. The perceived marginal damage depends on how the KP-USA's aggregate quota responds to an expansion in the USA's quota. Since the KP-USA's aggregate quota falls in response to an expansion in the USA's quota, the perceived marginal damage in the USA is lower than $\mathrm{G}_{\mathrm{E}}^{1}$.

Equation (18) allows us to implicitly define the USA's optimal quota level as a function of the price of the industrial good, $\mathrm{Q}^{1}(\mathrm{p})$. Inserting this function into equation (17) yields $\mathrm{m}^{1}(\mathrm{p}) \equiv \mathrm{M}^{1}\left(\mathrm{p}, \mathrm{Q}^{1}(\mathrm{p})\right) / \mathrm{n}_{1}$. Inserting $\mathrm{Q}^{1}(\mathrm{p})$ into equation (15) implies $\mathrm{Q}^{\Sigma}(\mathrm{p}) \equiv \mathrm{Q}^{\Sigma}\left(\mathrm{p}, \mathrm{Q}^{1}(\mathrm{p})\right)$. Plugging $\mathrm{Q}^{1}(\mathrm{p})$ and $\mathrm{Q}^{\Sigma}(\mathrm{p})$ into equation (13) yields $\mathrm{M}^{\Sigma}(\mathrm{p})$ and thus $\mathrm{w}^{\mathrm{k}}(\mathrm{p}) \equiv \mathrm{W}^{\mathrm{k}}\left(\mathrm{p}, \mathrm{M}^{\Sigma}(\mathrm{p})\right) / \mathrm{n}_{\mathrm{k}}$. Let 
$\mathrm{y}^{1}(\mathrm{p}) \equiv \mathrm{y}^{1}\left(\mathrm{p}, \mathrm{m}^{1}(\mathrm{p})\right), \quad \mathrm{y}^{\mathrm{k}}(\mathrm{p}) \equiv \mathrm{y}^{\mathrm{k}}\left(\mathrm{p}, \mathrm{w}^{\mathrm{k}}(\mathrm{p})\right), \quad \mathrm{r}^{1}(\mathrm{p}) \equiv \mathrm{p}-\mathrm{c}^{1}\left(\mathrm{p}, \mathrm{Q}^{1}(\mathrm{p})\right), \quad \mathrm{r}^{\mathrm{o}}(\mathrm{p}) \equiv \mathrm{p}-\mathrm{c}^{\mathrm{o}}\left(\mathrm{p}, \mathrm{Q}^{\mathrm{1}}(\mathrm{p})\right)$, $\overline{\mathrm{Y}}^{1}(\mathrm{p}) \equiv \overline{\mathrm{Y}}^{1}(\mathrm{p}, \mathrm{Q}(\mathrm{p})), \overline{\mathrm{Y}}^{\mathrm{k}}(\mathrm{p}) \equiv \overline{\mathrm{Y}}^{k}(\mathrm{p}, \mathrm{Q}(\mathrm{p}))$ and $\mathrm{Q}(\mathrm{p}) \equiv \mathrm{Q}^{1}(\mathrm{p})+\mathrm{Q}^{\mathrm{s}}(\mathrm{p})$. Then, the price of the industrial good is determined by:

$$
\sum_{j=1}^{J} n_{j} y^{j}(p)=\sum_{j=1}^{j}\left(Y_{j}^{0}+\bar{Y}^{j}(p)\right)+Y^{1}\left(r^{1}(p)\right)+\sum_{k=2}^{j} Y^{k}\left(r^{o}(p)\right)
$$

The equilibrium allocation of resources for the global economy in this setting is characterized by equations (3b), (4b), (10a), (10b), (11a), (11b), (12a), (12b), (13), (14a), (14b), (17), (18), (19) and the budget constraints, $\mathrm{x}_{1}+\mathrm{py}_{1}=\mathrm{m}_{1}$ and $\mathrm{x}_{\mathrm{k}}+\mathrm{py}_{\mathrm{k}}=\mathrm{w}_{\mathrm{k}}, \mathrm{k}=2, \ldots, \mathrm{J}$. Combining equations (4b), (10b) and (14b) yields

$$
\mathrm{G}_{\mathrm{Y}}^{\mathrm{k}}=\frac{1}{\mathrm{~F}_{\mathrm{X}}^{\mathrm{k}}}+\sum_{\mathrm{n}=2}^{\mathrm{J}} \mathrm{G}_{\mathrm{E}}^{\mathrm{k}} \cdot \quad \mathrm{k}=2, \ldots, \mathrm{J} .
$$

Combining equations (4b), (10a) and (18), we obtain

$$
\mathrm{G}_{\mathrm{Y}}^{1}=\frac{1}{\mathrm{~F}_{\mathrm{X}}^{1}}+\left(1+\frac{\mathrm{dQ}^{\Sigma}}{\mathrm{dQ}_{1}}\right) \mathrm{G}_{\mathrm{E}}^{1}
$$

Now consider the Pareto efficiency conditions (1f) for $\mathrm{j}=2, \ldots, \mathrm{J}$. Equations (20a) differ from their Pareto efficiency counterparts only in that they do not include the marginal damages caused to the USA. Equation (20b) differs from its Pareto efficiency counterpart in that it is perceived marginal damage does not correspond to the global marginal damage. It is also worth noting that the equilibrium conditions that tell us how interregional transfers are made do not correspond to their Pareto efficiency counterparts because the equilibrium conditions do not include transfers from or to the USA while Pareto efficiency requires interregional transfers be made across all regions in the globe.

For future reference, let $\mathrm{V}^{\mathrm{j} 1}$ be region j's per capita utility level realized in the global equilibrium allocation described in this section.

\subsection{Ideal Kyoto Protocol}

Suppose now that all regions in the globe, including the USA, participate in the Kyoto Protocol (KP). Regulators and the GEF play a two-stage game, whereby regulators commit to their environmental policies before the GEF implements interregional transfers. The equilibrium concept for the two-stage game is again subgame perfection. 
Let $\mathrm{c}$ denote the global price of an emission permit. Assuming that $\mathrm{p}>\mathrm{c}$, each region's industrial sector maximizes profit if and only if

$$
-(p-c) F_{x}^{j}=1, \quad j=1, \ldots, J .
$$

Let $r \equiv p-c$. Equations (21) enable us to define $\bar{X}^{j}(r), j=1, \ldots, J$. Hence, $Y^{j}(r) \equiv F^{j}\left(\bar{X}^{j}(r)\right), j=1, \ldots, J$. As before, equations (4b) yield the regional agricultural sectors' input functions $\bar{Y}^{j}(p, Q), j=1, \ldots, J$. Thus, $X^{\mathrm{j}}(p, Q) \equiv G^{\mathrm{j}}\left(\bar{Y}^{\mathrm{j}}(p, Q), Q\right), j=1, \ldots, J$.

The global market for emission permits clears if and only if

$$
\sum_{j=1}^{J} Y^{j}(r)=Q
$$

Equation (22) permits us to define $c(p, Q)$. It is easy to verify that $c_{Q}=-1 / \sum_{j=1}^{J} Y_{r}^{j}<0$. We can now define $\Pi^{j}(p, Q) \equiv\left\{(p-c(p, Q)) Y^{j}(p-c(p, Q))+\bar{X}^{j}(p-c(p, Q))\right\}+\left\{X^{j}(p, Q)+p \bar{Y}^{j}(p, Q)\right\}$, the total profit in region $j .$.

Let $\mathrm{w}_{\mathrm{j}} \equiv \mathrm{m}_{\mathrm{j}}+\mathrm{T}_{\mathrm{j}} / \mathrm{n}_{\mathrm{j}}$ be per capita income in region $\mathrm{j}$. The redistribution constraint for the interregional transfers is now $\sum_{j=1}^{J} T_{j}=0$. The demand functions for the representative consumer in region $\mathrm{j}$ are $\mathrm{x}^{\mathrm{j}}\left(\mathrm{p}, \mathrm{w}_{\mathrm{j}}\right)$ and $\mathrm{y}^{\mathrm{j}}\left(\mathrm{p}, \mathrm{w}_{\mathrm{j}}\right)$. His indirect utility function is $\mathrm{V}^{\mathrm{j}}\left(\mathrm{p}, \mathrm{w}_{\mathrm{j}}\right) \equiv \mathrm{U}^{\mathrm{j}}\left(\mathrm{x}^{\mathrm{j}}\left(\mathrm{p}, \mathrm{w}_{\mathrm{j}}\right), \mathrm{y}^{\mathrm{j}}\left(\mathrm{p}, \mathrm{w}_{\mathrm{j}}\right)\right)$.

Taking $\mathbf{p}, \mathbf{Q} \equiv\left(\mathrm{Q}_{1}, \ldots, \mathrm{Q}_{\mathrm{J}}\right)$ and $\mathbf{m} \equiv\left(\mathrm{m}_{1}, \ldots, \mathrm{m}_{\mathrm{J}}\right)$ as given, the GEF chooses $\left\{\mathrm{W}_{\mathrm{j}}\right\}_{\mathrm{j}=1, \ldots, \mathrm{J}}$ to $\operatorname{maximize} \sum_{\mathrm{j}=1}^{\mathrm{J}} \theta_{\mathrm{j}} \mathrm{V}^{\mathrm{j}}\left(\mathrm{p}, \mathrm{W}_{\mathrm{j}} / \mathrm{n}_{\mathrm{j}}\right)$ subject to:

$$
\sum_{j=1}^{J} W_{j}=\sum_{j=1}^{J} M_{j} \equiv M
$$

where $\theta_{j}>0$ for all $\mathrm{j}$ and $\sum_{j=1}^{\mathrm{J}} \theta_{\mathrm{j}} \equiv 1$. Besides equation (23a), the first order conditions for maximization can be written as follows:

$$
\frac{\theta_{j} U_{x}^{j}\left(x^{j}\left(p, W_{j} / n_{j}\right), y^{j}\left(p, W_{j} / n_{j}\right)\right)}{n_{j}}=\eta, \quad j=1, \ldots, J
$$


where $\eta>0$ is the Lagrangian multiplier associated with constraint (23a). Equations (23b) demonstrate that the GEF implements transfers in order to equalize individual marginal utilities of income across all regions in the globe. These conditions, therefore, satisfy the Pareto efficiency requirement that the individual marginal shadow utilities of income be equalized across all regions of the globe. Note that equations (23b) are identical to equations (2c) provided that $\lambda_{\mathrm{k}}=\theta_{\mathrm{k}} / \theta_{1}, \mathrm{k}=2, \ldots, \mathrm{J}$.

Equations (23) enable us to define $\mathrm{W}^{\mathrm{j}}(\mathrm{p}, \mathrm{M}), \mathrm{j}=1, \ldots, \mathrm{J}$. Plugging these functions into equation (23a) yields

$$
\sum_{j=1}^{J} W^{j}(p, M)=M
$$

Differentiating equation (23c) with respect to $\mathrm{M}$, we obtain

$$
\sum_{j=1}^{J} W_{M}^{j}=1
$$

where $\mathrm{W}_{\mathrm{M}}^{\mathrm{j}} \equiv \partial \mathrm{W}^{\mathrm{j}} / \partial \mathrm{M}, \mathrm{j}=1, \ldots, \mathrm{J}$.

The global income level, M, is the sum of all regions' initial endowments and profits. Then,

$$
\mathrm{M}=\mathrm{c}(\mathrm{p}, \mathrm{Q}) \mathrm{Q}+\sum_{\mathrm{j}=1}^{\mathrm{J}}\left(\mathrm{X}_{\mathrm{j}}^{0}+\mathrm{p} \mathrm{Y}_{\mathrm{j}}^{0}+\Pi^{\mathrm{j}}(\mathrm{p}, \mathrm{Q})\right) .
$$

In the first stage of the game, regulator $\mathrm{j}$ chooses nonnegative $\left\{\mathrm{Q}_{\mathrm{j}}\right\}$ to maximize $\mathrm{W}^{\mathrm{j}}(\mathrm{p}, \mathrm{M})$ subject to equation (25), taking $\mathrm{p}$ and the choice of every other regulator as given. Assuming that the solution to each regulator's problem is interior, the first order conditions that characterize the Nash equilibrium in the first stage of the game are

$$
\mathrm{W}_{\mathrm{M}}^{\mathrm{j}}\left(\mathrm{c}+\sum_{\mathrm{I}=1}^{\mathrm{J}} \mathrm{G}_{\mathrm{E}}^{\mathrm{i}}\right)=0, \quad \mathrm{j}=1, \ldots, \mathrm{J} .
$$

Given equation (24c), we obtain the following result when we add up equations (26a) over all $\mathrm{j}$ :

$$
\left(\mathrm{c}+\sum_{\mathrm{i}=1}^{\mathrm{J}} \mathrm{G}_{\mathrm{E}}^{\mathrm{i}}\right) \sum_{\mathrm{J}=1}^{\mathrm{J}} \mathrm{W}_{\mathrm{M}}^{\mathrm{j}}=\left(\mathrm{c}+\sum_{\mathrm{i}=1}^{\mathrm{J}} \mathrm{G}_{\mathrm{E}}^{\mathrm{i}}\right)=0,
$$

or

$$
c(p, Q)=-\sum_{i=1}^{J} G_{E}^{i}\left(\bar{Y}^{i}(p, Q), Q\right) .
$$


Equation (26b) determines the equilibrium global quota level. It shows that each regulator agrees on a price of permits equal to the global marginal damages caused by carbon dioxide emissions. The interregional transfers implemented by the GEF induces each regulator to choose a regional quota level that maximizes global income. Hence, each regulator finds it desirable to acknowledge the negative effects brought about by production of the industrial good in his region.

Equation (26b) enables us to define the global quota of emission permits as a function of the price of the industrial good, $\mathrm{Q}(\mathrm{p})$. Inserting this function into equation (25), we obtain $\mathrm{M}(\mathrm{p})$. Hence, we can define $\mathrm{w}^{\mathrm{j}}(\mathrm{p}) \equiv \mathrm{W}^{\mathrm{j}}(\mathrm{p}, \mathrm{M}(\mathrm{p})) / \mathrm{n}_{\mathrm{j}}$ and $\mathrm{y}^{\mathrm{j}}(\mathrm{p}) \equiv \mathrm{y}^{\mathrm{j}}\left(\mathrm{p}, \mathrm{w}^{\mathrm{j}}(\mathrm{p})\right)$. Let $\mathrm{r}^{\mathrm{j}}(\mathrm{p}) \equiv \mathrm{p}-\mathrm{c}(\mathrm{p}, \mathrm{Q}(\mathrm{p}))$ and $\mathrm{Y}^{\mathrm{j}}(\mathrm{p}) \equiv \mathrm{Y}^{\mathrm{j}}\left(\mathrm{r}^{\mathrm{j}}(\mathrm{p})\right)$. Let also $\overline{\mathrm{Y}}^{\mathrm{j}}(\mathrm{p}) \equiv \overline{\mathrm{Y}}^{\mathrm{j}}(\mathrm{p}, \mathrm{Q}(\mathrm{p}))$. Hence, the price of the industrial good is determined by the following market clearing condition:

$$
\sum_{j=1}^{J} n_{j} y^{j}(p)=\sum_{j=1}^{J}\left(Y_{j}^{0}+Y^{j}(p)+\bar{Y}^{j}(p)\right) .
$$

The global equilibrium allocation of resources in this setting is characterized by equations ( $3 b$ ), (4b), (21), (22), (23a), (23b), (25), (26a), (26b), (27) and the budget constraints, $x_{j}+p y_{j}=w_{j}, j=1, \ldots, J$. Equations (3b) and (4b) imply that the equilibrium allocation satisfies the Pareto efficiency conditions (1d) and (1e), respectively. Furthermore, equations (4b), (21) and (26b) together yield the Pareto efficiency conditions (1f). Since we have already established that the equilibrium allocation satisfies the Pareto efficiency conditions underlying interregional transfers, we can state this paper's main result as follows:

Theorem 1: Provided that all regions in the globe participate in the Kyoto Protocol and $Q_{j}>0$ for all $j$ in the subgame perfect equilibrium for the policy game played by the regional regulators and the GEF, the implied equilibrium allocation of resources for the global economy is Pareto efficient.

Theorem 1 is extremely important in light of the USA's decision to withdraw from the Kyoto Protocol and the current set of events, in which some countries, such as Russia and Japan, are still unsure whether or not they should ratify the Protocol. The efficiency properties of the Ideal Kyoto Protocol scheme, clearly described in Theorem 1, imply that there is potential for each region in the globe to 
improve its welfare level relative to what it obtains in the status quo. To see this formally, let $\mathrm{V}^{\mathrm{J} *}$ denote region j's welfare level in the equilibrium described in this section. Because the equilibrium allocation implied by the Ideal Kyoto Protocol scheme is Pareto efficient and the equilibrium allocations implied by regional policy making and the KP-USA scheme are inefficient, we have

$$
\begin{aligned}
& \sum_{j=1}^{J} n_{j} V^{j^{*}}>\sum_{j=1}^{J} n_{j} V^{j 0}, \\
& \sum_{j=1}^{J} n_{j} V^{j^{*}}>\sum_{j=1}^{J} n_{j} V^{j 1} .
\end{aligned}
$$

Inequality (28a) tell us that the Ideal Kyoto Protocol scheme can satisfy all regions' participation constraints if the status quo is characterized by regional policy making - i.e., if the Kyoto Protocol fails. Similarly, inequality (28b) states that all regions' participation constraints can also be satisfied by the Ideal Kyoto Protocol scheme if the status quo is characterized by a setting in which the USA is the only region that does not participate in the Kyoto Protocol. An interesting implication of inequality (28) is that there is scope for bribing the USA to reverse its withdraw decision. The bribe would have to satisfy

$$
\mathrm{V}^{1^{*}} \geq \mathrm{V}^{11}
$$

while, at the same time, not violating

$$
\mathrm{V}^{\mathrm{k}^{*}} \geq \mathrm{V}^{\mathrm{k} 1}, \quad \mathrm{k}=2, \ldots, \mathrm{J} .
$$

Now, notice that inequality (28b) implies that inequality (29a) as well as the set of J-1 inequalities (29b) can all be satisfied slack. Not only would the USA be better off by reversing its withdraw decision, but also every other region in the globe would benefit from conceding to terms - i.e., the bribe - that would persuade the USA to reverse its decision!

Our global economy does not explicitly distinguish developed from developing regions. How does our analysis then capture the Kyoto Protocol's intention of transferring resources from developed to developing regions? Since the levels of per capita income are higher in developed regions than in developing regions, the marginal utilities of income are lower in developed regions. Given the exogenous weights assigned to regional welfare levels, the redistributive transfer mechanism operated by the GEF transfers resources from regions whose weighted marginal utilities of income are low to regions whose weighted marginal utilities of income are high. If, for example, the weights are equal across all regions, the 
transfer mechanism will necessarily transfer resources from developed to developing regions. Indeed, it can be shown that there is a large number of weight allocations that would imply resource transfers from developed to developing regions without violating the participation constrains (29a) and (29b).

It must also be stressed that our efficiency result depends crucially on the timing of the policy game played by regional regulators and the GEF. ${ }^{6}$ It is, for example, straightforward to show that if the timing of the game were changed so that the GEF "moved" first and the regional regulators "moved" last, the implied subgame perfect equilibrium would not feature condition (26b) because the regulators would not attempt to maximize global income. Since they would essentially treat the GEF transfers as lump-sum transfers, their decisions would not depend on such transfers. Each regulator would choose a policy that maximizes regional income, neglecting therefore the negative externalities caused by regional emissions.

Fortunately, our assumption about the timing of the policy game appears to be consistent with reality. The GEF cannot possibly be a Stackelberg leader. Because it is incapable of punishing nations for not complying with environmental standards, it lacks political and economical powers to design and enforce interregional schemes to control emissions of carbon dioxide. Not surprisingly, design and enforcement of the Kyoto Protocol are responsibilities of the participating nations. As we mentioned in the introduction, the Conference of the Parties to the United Nations Framework Convention on Climate Change, which represents the supreme body of the Convention, delegated authority to the GEF to operate the financial mechanism. Therefore, it appears quite reasonable to postulate that the GEF is a common Stackelberg follower in the policy game played with regional regulators.

\section{Conclusion}

In this paper, we demonstrate that there is a combination of emissions trading and transfer mechanisms that yields an efficient allocation of resources for a global economy. The transfer mechanism should be redistributive and operated after the regional governments make their policy commitments regarding how to control regional emissions of carbon dioxide. Furthermore, there should be global participation in both mechanisms. An interregional scheme featuring global participation and the efficient mix of mechanisms and timing of operations described above is what an ideal Kyoto Protocol should look like.

\footnotetext{
${ }^{6}$ Our efficiency result, however, does not depend on our game being a quantity leadership game rather than a price leadership game. Changing the strategy space would not alter the incentives of regulators of maximizing global income in the first stage of the game.
} 


\section{References}

Arce, Daniel, 2001, "Leadership and the Aggregation of International Collective Action," Oxford Economic Papers, 53: 114-137.

Barrett, Scott, 1994, "Self-Enforcing International Environmental Agreements," Oxford Economic Papers, 46: 878-894.

Black, Jane, Maurice D. Levi, and David De Meza, 1993, "Creating a Good Atmosphere: Minimum Participation for Tackling the 'Greenhouse Effect'", Economica, 60: 281-293.

Caplan, Arthur J. and Emilson C. D. Silva, 2002, "An Equitable, Efficient and Implementable Scheme to Control Global Carbon Dioxide Emissions," unpublished manuscript.

Caplan, Arthur J., Richard C. Cornes and Emilson C. D. Silva, 2000, "Pure Public Goods and Income Redistribution in a Federation with Decentralized Leadership and Imperfect Labor Mobility, Journal of Public Economics, 77: 265-284.

Chichilnisky, G., G. Heal and D. Starrett, 2000, "Equity and Efficiency in Environmental Markets: Global Trade in Carbon Dioxide Emissions," in Environmental Markets: Equity and Efficiency, G. Chilchinisky and G. Heal (eds.), Columbia University Press, New York

Coggins, Jay S. and John R. Swinton, 1996, “The Price of Pollution: A Dual Approach to Valuing $\mathrm{SO}_{2}$ Allowances," Journal of Environmental Economics and Management, 30: 58-72.

Hahn, Robert W., 1989, "Economic Prescriptions For Environmental Problems: How the Patient Followed the Doctor's Orders," Journal of Economic Perspectives, 3(2): 95-114.

Kyoto Protocol to the United Nations Framework Convention on Climate Change, December 10, 1997.

Maloney, Michael T. and Bruce Yandle, 1984, "Estimation of the Cost of Air Pollution Control Regulation," Journal of Environmental Economics and Management, 11: 244-263.

Stavins, Robert N., 1998, "What Can We Learn from the Grand Policy Experiment? Lessons from $\mathrm{SO}_{2}$ Allowance Trading," Journal of Economic Perspectives, 12(3): 69-88. 